\title{
Cerebro-umbilical doppler ratio as a predictor of adverse perinatal outcome
}

\section{A. Esther Kamalarani*, Sheba Rosette Victor}

Department of Obstetrics and Gynecology, Tirunelveli Medical College Hospital, Tamil Nadu, India

Received: 30 November 2019

Revised: 27 December 2019

Accepted: 02 January 2020

\section{*Correspondence:}

Dr. A. Esther Kamalarani,

E-mail: estherkamalarani@gmail.com

Copyright: (c) the author(s), publisher and licensee Medip Academy. This is an open-access article distributed under the terms of the Creative Commons Attribution Non-Commercial License, which permits unrestricted non-commercial use, distribution, and reproduction in any medium, provided the original work is properly cited.

\begin{abstract}
Background: Intrauterine growth restriction (IUGR) is defined as a subnormal bodyweight or mass in utero. Fetal Doppler studies have been identified as one of the reliable and non-invasive methods of antepartum fetal surveillance in growth-restricted fetuses to detect hypoxemia and to plan timely delivery to precede acidemia. The aim of this study is to evaluate the screening efficacy of the pulsatility indices (PI) of the umbilical artery (UA) and middle cerebral artery (MCA) and the ratio of these two indices in predicting the adverse perinatal outcome in pregnancies complicated by IUGR.

Methods: In this study patients were included after diagnosed to have fetal growth restriction clinically by a disparity of four weeks or more between symphysis-fundal height and gestational age and on the serial measurement of symphysis-fundal height after 30 weeks of gestation.

Results: Out of 100 patients who fulfilled the criteria for the study, only 85 patients delivered. Out of them, only 16 women $(18.8 \%)$ had a ratio of $<1.08$ which was considered abnormal and the rest of the women $(81.2 \%)$ had a ratio $>1.08$ which was considered normal. The specificity for the Cerebro-umbilical ratio $(<1.08)$ to predict adverse perinatal outcome was $96 \%$ whereas that for PI of umbilical A (>1.12) was $83 \%$ and that for the PI of middle cerebral A $(<1.2)$ was $84 \%$. However, the sensitivities for these indices were very low.

Conclusions: The ratio of the pulsatility indices of the umbilical artery and middle cerebral artery is useful to predict the adverse perinatal outcome.
\end{abstract}

Keywords: Fetal doppler- pulsatility index, Intrauterine growth restriction, Perinatal outcome

\section{INTRODUCTION}

IUGR is defined as subnormal body weight or mass. Battaglia et al, defined small for gestational age (SGA) new-borns as those, whose weights were below the tenth percentile for their gestational age. ${ }^{1}$ With the development of ultrasound technology, we are able to identify small fetuses in the uterus and the term IUGR is used for the fetuses with the estimated weight below the tenth percentile for their gestational age. IUGR may result from a number of pathologies in either the mother or the fetus causing a decrease in the cell size and when severe, cell number also. Intire $\mathrm{Mc}$ et al, found that the mortality and morbidity were significantly increased in new-borns with their birthweights below the third percentile for their gestational age. ${ }^{2}$ Various methods of antepartum surveillance available help to detect hypoxic fetuses and to plan delivery before acidemia sets in. Fitzgerald and Drumm first reported the use of doppler ultrasound to investigate human fetal circulation. ${ }^{3}$ Doppler ultrasound helps to detect the hemodynamic changes that reflect fetal compromise in pregnancies complicated by IUGR, pregnancy-induced hypertension, Rh-isoimmunisation, discordant twins and post-term 
pregnancies. Grammelini et al, had shown the effectiveness of combined umbilical and cerebral artery indices in predicting the poor perinatal outcome in IUGR fetuses than individual indices alone. ${ }^{4}$ When hypoxemia is caused by uteroplacental dysfunction, the typical progression begins with increased resistance in the umbilical A, is followed by decreased resistance in the middle cerebral $\mathrm{A}$ and is completed with the development of abnormal venous waveforms as cardiac function deteriorates. This compensatory adjustment is called "The brain sparing effect".

The aim of this study was to evaluate the screening efficacy of the pulsatility indices (PI) of the umbilical artery (UA) and middle cerebral artery (MCA) and the ratio of these two indices in predicting the adverse perinatal outcome in pregnancies complicated by IUGR.

\section{METHODS}

The study was carried out in the department of obstetrics and gynaecology in TVMCH over a period of one year. The patients included in the study were diagnosed to have fetal growth restriction clinically - 1) by a disparity of four weeks or more between symphysis-fundal height and gestational age. 2) on the serial measurement of symphysis-fundal height after 30 weeks of gestation.

\section{Inclusion criteria}

- Women who had regular menstrual cycles prior to conception and sure of their last menstrual period (LMP) or whose gestational age had been established by first-trimester USG

- Women who had a singleton pregnancy

- Gestational age between 30-40 weeks of pregnancy

- Women identified to have IUGR, women with highrisk pregnancies like PIH, hypertension complicating pregnancy etc.

\section{Exclusion criteria}

- Women with fetuses with major congenital malformations diagnosed by antenatal USG.

Doppler examinations were performed. Studies were done in antenatal OPD with the patient in semirecumbent position and the fetus in a quiet resting state, ie. when there was no irregularity of arterial waveforms and swaying of the venous waveforms. Doppler determinations were done by two consultants in the department.

Umbilical artery flow velocity waveform recordings were obtained by placing the sample volume on the artery away from the placental and fetal cord insertions. After a satisfactory waveform was obtained, PI of the three best cardiac cycles was calculated and an average was taken. Similarly, MCA pulsations were identified in the Sylvian fissure by imaging the head in transverse section plane. The doppler sample was placed and flow velocity waveforms obtained. PI of three best cardiac cycles was calculated and an average was taken. Doppler studies were repeated every 3 to 4 weeks and the last values before delivery were taken for the study. Decisions on induction and cesarean section were based on clinical findings and other fetal surveillance tests like NST and biophysical profile as per the standards of the department.

A cerebro-umbilical ratio of 1.08 was used as a cut off as per the study of Grammelini et al. This cut off was -2 standard deviations from the mean of cerebro-umbilical ratios of normal patients between 30 to 40 weeks. A cerebro-umbilical ratio at or below this cut off was considered to be abnormal. A value above this cut off was considered normal. In both groups women were followed at the time delivery and the following outcomes were studied: 1) Gestational age at birth, 2) birth weight, 3) Apgar score at 5 minutes (below 7), 4) cesarean section delivery rate for fetal distress, 5) meconium staining of amniotic fluid, 6) number of days of stay in NICU, 7) neonatal complications like hypoglycemia, hypothermia, hyperbilirubinemia, meconium aspiration syndrome and sepsis, 8) perinatal death. PI cutoff value of 1.12 for the umbilical artery and 1.2 for middle cerebral artery respectively was also taken for the study.

\section{Statistical analysis}

The sample size was calculated. As per the previous studies, the proportion of women with abnormal cerebroumbilical ratio was $40 \%$ of those with IUGR. Allowing a differential error of $10 \%$, it was calculated as 96 patients. The analysis was done using SPSS PC+ software. A comparison of the different variables was performed with the student's ' $T$ ' test. A $p$ value of $<0.05$ was taken to be significant.

\section{RESULTS}

A total 100 women who fulfilled the criteria for the study with clinically diagnosed IUGR were included and the doppler studies were done. Out of these 85 patients delivered and the outcomes were analyzed. 2 patients were excluded because of the change of LMP during subsequent visits. 13 patients delivered elsewhere. The various maternal characteristics and the perinatal outcomes between the two groups with a cut off value of 1.08 were compared. 16 women of $85(18.8 \%)$ had a ratio of $<1.08$ (abnormal) and 69 women $(81.2 \%$ ) had a ratio of $>1.08$ (normal). Considering the demographic factors, more women with abnormal values were multigravida compared to primigravida (62.5\% versus $37.5 \%)$. Around $62.5 \%$ were from low socioeconomic status. Women with antenatal risk factors like PIH, HT complicating pregnancy, H/o delivery of SGA babies in previous pregnancies, vascular disorders like APLA syndrome and uterine anomalies with IUGR were more likely to have abnormal doppler values (Table 1 and 2). 
Table 1: General characteristics of study patients.

\begin{tabular}{|llll|}
\hline Variables & Cerebral - umbilical ratio $(\leq \mathbf{1 . 0 8}) \mathbf{n}=\mathbf{1 6}$ & Cerebral - umbilical ratio $(>\mathbf{1 . 0 8}) \mathbf{n}=\mathbf{6 9}$ & $\mathbf{p}$-value \\
\hline Age & $25.4 \pm 5.7$ & $24.5 \pm 4.9$ & 0.511 \\
\hline Height & $155.6 \pm 8.5$ & $156.5 \pm 5.5$ & 0.677 \\
\hline Weight & $53.8 \pm 8.3$ & $55.4 \pm 9.5$ & 0.529 \\
\hline Primi & $6(37.5 \%)$ & $40(58 \%)$ & 0.142 \\
\hline Multi & $10(62.5 \%)$ & $29(42 \%)$ & 0.154 \\
\hline
\end{tabular}

Table 2: Antenatal risk factors.

\begin{tabular}{|c|c|c|c|}
\hline Antenatal risk factors & $\begin{array}{l}\text { Cerebral - umbilical ratio }(\leq 1.08) \\
n=16\end{array}$ & $\begin{array}{l}\text { Cerebral - umbilical ratio } \\
(>1.08) n=69\end{array}$ & p-value \\
\hline Pregnancy induced hypertension & $5(31.3 \%)$ & $14(20.3 \%)$ & 0.34 \\
\hline Hypertension complicating pregnancy & $1(6.3 \%)$ & $1(1.4 \%)$ & 0.82 \\
\hline Previous SGA babies & $4(25 \%)$ & $6(8.7 \%)$ & 0.16 \\
\hline Vascular disorders & $2(12.5 \%)$ & - & - \\
\hline Antenatal risk factors & $12(75 \%)$ & $21(30 \%)$ & 0.002 \\
\hline Maternal infection & $2(12.5 \%)$ & $3(4.3 \%)$ & 0.509 \\
\hline
\end{tabular}

Table 3: Mode of delivery.

\begin{tabular}{|c|c|c|c|}
\hline Mode of delivery & Cerebral - umbilical ratio $(\leq 1.08) n=16$ & Cerebral - umbilical ratio $(>1.08) n=69$ & $\mathrm{p}$-value \\
\hline Normal & $8(50 \%)$ & $40(58 \%)$ & 0.56 \\
\hline Forceps & - & $6(8.7 \%)$ & - \\
\hline Suction cup & - & $3(4.3 \%)$ & - \\
\hline LSCS & $8(50 \%)$ & $20(29 \%)$ & 0.107 \\
\hline
\end{tabular}

Table 4: Perinatal outcome.

\begin{tabular}{|c|c|c|c|c|}
\hline \multicolumn{2}{|c|}{ Perinatal outcome } & $\begin{array}{l}\text { Cerebral - umbilical ratio }(\leq 1.08) \\
\mathrm{n}=16\end{array}$ & $\begin{array}{l}\text { Cerebral - umbilical ratio } \\
(>1.08) n=69\end{array}$ & p-value \\
\hline \multicolumn{2}{|c|}{ Birth weight (grams) } & $1872.5 \pm 372.6$ & $2383.6 \pm 357.1$ & $<0.0001$ \\
\hline \multirow{2}{*}{$\begin{array}{l}\text { Baby } \\
\text { gender }\end{array}$} & Male & $9(56.3 \%)$ & $34(49.3 \%)$ & - \\
\hline & Female & $7(43.8 \%)$ & $35(50.7 \%)$ & 1 \\
\hline \multicolumn{2}{|c|}{ Placenta weight (grams) } & $362.5 \pm 69.5$ & $440.9 \pm 102.3$ & 0.005 \\
\hline \multirow{2}{*}{ Apgar score } & 1 min score $<5$ & $1(6.25 \%)$ & $5(7.24 \%)$ & - \\
\hline & 5 min score $<7$ & $1(6.25 \%)$ & $6(8.69 \%)$ & - \\
\hline \multicolumn{2}{|c|}{ Umbilical artery $\mathrm{pH}$} & $7.21 \pm 0.07$ & $7.20 \pm 0.11$ & - \\
\hline \multirow{2}{*}{$\begin{array}{l}\text { Nursery day } \\
\text { care }\end{array}$} & $>4$ days & $11 / 14(78.6 \%)$ & $14 / 21(66.7 \%)$ & - \\
\hline & $>7$ days & $7 / 14(50 \%)$ & $7 / 21(33.3 \%)$ & - \\
\hline
\end{tabular}

Table 5: Neonatal complications.

\begin{tabular}{|c|c|c|c|c|}
\hline Neonatal complications & $\begin{array}{l}\text { Cerebral - umbilical } \\
\text { ratio }(\leq 1.08) \mathrm{n}=16\end{array}$ & $\begin{array}{l}\text { Cerebral - umbilical } \\
\text { ratio }(>1.08) n=69\end{array}$ & p-value & $\begin{array}{l}\text { Odds ratio }(95 \%) \\
\text { CI) }\end{array}$ \\
\hline Hypothermia & - & $1(1.4 \%)$ & - & - \\
\hline Meconium aspiration syndrome & - & $2(2.9 \%)$ & - & - \\
\hline Polycythemia & $1(6.3 \%)$ & - & - & - \\
\hline Hyperbilirubinemia & $10(62.5 \%)$ & $16(23.2 \%)$ & 0.002 & $5.52(1.53-20.66)$ \\
\hline Sepsis & - & $1(1.4 \%)$ & - & $9.71(0.62-292.7)$ \\
\hline Fetal anomalies & $2(12.5 \%)$ & $1(1.4 \%)$ & 0.15 & $0.4(0.03-0.53)$ \\
\hline No complications & $4(25 \%)$ & $49(71 \%)$ & 0.001 & 1 \\
\hline
\end{tabular}


A total 22 women had abnormal PI UA values i.e.., > 1.12 (cut off 1.12) and 16 women had abnormal PI MCA values i.e.. $<1.2$ (cut off 1.2). 2 women had absent enddiastolic flow and delivered by LSCS - one had severe pre-eclampsia and one baby had features of Down's syndrome. $50 \%$ of women with abnormal Cerebroumbilical ratio had to be delivered by LSCS compared to $29 \%$ in the normal group. LSCS for fetal distress was done for $31.3 \%$ in abnormal group compared to $10 \%$ in the normal group with $\mathrm{p}$ value of 0.07 (Table 3 ).
Considering the perinatal outcome, the mean birth weight was $1872.5 \pm 372.6 \mathrm{gms}$ in the abnormal group compared to $2383.6 \pm 357.1 \mathrm{gms}$ in the normal group with a $\mathrm{p}$ value of 0.00 . There was a significant difference in placental weight also $(362.5 \pm 69.5$ versus $440.9 \pm 102.3$ gms) with $p$ value of 0.005 . A number of babies who required nursery care for $>7$ days were more in the abnormal group $(50 \%$ versus $33.3 \%$ ). The incidence of hyperbilirubinemia was high in the abnormal group (62.5\% versus $23.2 \%)$. Babies with no complications were less in the abnormal group (25\% versus $71 \%$ ) with p value of 0.001 (Table 4 7).

Table 6: Efficacy of Doppler indices in IUGR identifying small for gestational age babies.

\begin{tabular}{|lllll|}
\hline Variables & Sensitivity & Specificity & PPV & NPV \\
\hline Cerebral - umbilical ratio & $68.70 \%$ & $53.60 \%$ & $25.60 \%$ & $88.10 \%$ \\
\hline Umbilical artery pulsatility index & $63.40 \%$ & $53.90 \%$ & $32.60 \%$ & $81 \%$ \\
\hline Middle cerebral artery pulsatility index & $56 \%$ & $50.70 \%$ & $20.90 \%$ & $83.30 \%$ \\
\hline
\end{tabular}

Table 7: Birth weight percentile.

\begin{tabular}{|c|c|c|c|}
\hline $\begin{array}{l}\text { Birth weight } \\
\text { percentile }\end{array}$ & $\begin{array}{l}\text { Cerebral - umbilical ratio }(\leq 1.08) n= \\
16\end{array}$ & $\begin{array}{l}\text { Cerebral - umbilical ratio }(>1.08) n= \\
69\end{array}$ & $\begin{array}{l}P \text { - } \\
\text { value }\end{array}$ \\
\hline$<10^{\text {th }}$ percentile & $11(68.8 \%)$ & $32(46.4 \%)$ & \multirow{2}{*}{0.186} \\
\hline$>10^{\text {th }}$ percentile & $5(31.3 \%)$ & $37(53.6 \%)$ & \\
\hline
\end{tabular}

\section{DISCUSSION}

IUGR is associated with substantial perinatal morbidity and mortality. So fetuses at risk of hypoxemia should be identified and the timing of delivery must be planned. ${ }^{5}$ Previous studies done by Gramellini et al, Arias et al and Singh et al had concluded that Cerebro umbilical ratio was superior to individual doppler indices in predicting the adverse perinatal outcome.$^{4,6,7}$ Gramellini et al studied women with normal pregnancies and obtained a cutoff value of 1.08 for the Cerebro umbilical ratio. ${ }^{4}$ This was ' -2 ' standard deviation of the mean of the values obtained between 30- 41 weeks. The women were divided into 2 groups based on this cutoff value- a value of $<1.08$ was considered abnormal and a value of $>1.08$ was taken as normal. The adverse perinatal outcomes were analyzed in both groups.

In the abnormal ratio group, the percentage of women belonging to lower socioeconomic status was significantly higher than in the normal group $(62.5 \%$ versus $29 \%$ ) with a $\mathrm{p}$ value of 0.023 . A similar finding was reported by other authors. ${ }^{8}$

The percentage of women with antenatal risk factors like $\mathrm{PIH}$, hypertension complicating pregnancy, vascular disorders, maternal infection and delivery of SGA babies in the previous pregnancies were found to be higher in the abnormal ratio group, though it was statistically insignificant. ${ }^{5,9,10}$ Similarly when there is IUGR associated with antenatal risk factors, there is more chance of having an abnormal ratio (69\% versus $25 \%$ ) with a $\mathrm{p}$ value of 0.002 .

The number of women who underwent cesarean section was significantly more in the abnormal ratio group $(31.3 \%$ versus $5.8 \%)$ and the $\mathrm{p}$ value is 0.01 and $\mathrm{CI}$ is 1.41-40.45. The indications for the cesarean section being absent end-diastolic flow, severe oligohydramnios and ominous NST. The gestational age at delivery in the abnormal group was significantly lower than in the normal ratio group $(37.1 \pm 2.3$ versus $38.5 \pm 1.5$ weeks $)$ with $\mathrm{p}$ value of 0.003 . In Gramellini et al study it was still lower $(34.9 \pm 3.6$ weeks $){ }^{4}$

Number of cesarean sections done for the indication of fetal distress was higher in abnormal ratio group than in the normal ratio group ( $31.25 \%$ versus $10.14 \%)$. In the studies by Gramellini et al and Arias et al, this was still higher. ${ }^{4,6}$

The mean birth weight of babies in the abnormal ratio group was $1872.5 \pm 372.6$ grams, whereas it was $2383.6 \pm 357.2$ grams in the normal ratio group ('p' value 0.001). This has been shown in the study of Gramellini et al also. ${ }^{4}$ There was not much difference in the 1 minute and 5 minutes Apgar scores in both the groups. Prolonged NICU stay (> 7 days) was required for babies of women with an abnormal ratio (50\% versus $33 \%$ ), the reason being mainly prematurity and for weight gain. The study 
by Singh et al also showed that $75 \%$ of babies of the abnormal group stayed in the nursery for $>10$ days. $^{7}$

The number of newborns who developed neonatal complications like polycythemia and hyperbilirubinemia was more in the abnormal ratio group. Two babies in the abnormal ratio group had congenital anomalies- one baby had multiple anomalies like microcephaly, anophthalmos, rocker-bottom feet etc and another baby had features of Down's syndrome. In Arias et al study 3 babies had congenital anomalies. ${ }^{6}$ In this study, $50.5 \%$ of babies had birth weights below the tenth percentile. Out of this $68.8 \%$ belongs to the abnormal ratio group. There were no perinatal deaths in this study.

Receiver operator characteristics curves were plotted with different cutoff values. The specificity for the cerebro umbilical ratio $(<1.08)$ to predict adverse perinatal outcome was $96 \%$ whereas that for the PI of umbilical artery (> 1.12) was $83 \%$ and for the PI of a middle cerebral artery $(<1.2)$ the was $84 \%$. But the sensitivity for these indices was very low. Gramellini et al also noted that the specificity and the positive predictive value of $98.4 \%$ and $94.4 \%$ respectively for the Cerebro umbilical ratio and sensitivity of $68 \%$ in predicting the adverse perinatal outcome. ${ }^{4}$

The pulsatility indices of the umbilical and middle cerebral arteries are useful to predict the adverse perinatal outcome. But the abnormal cerebro umbilical ratio is better for predicting adverse perinatal outcomes such as fetal distress, SGA babies and neonatal complications like hyperbilirubinemia in cases of IUGR along with the other antenatal surveillance tests.

\section{CONCLUSION}

The pulsatility indices of the umbilical artery and middle cerebral artery are useful to predict the adverse perinatal outcome. But the abnormal cerebro-umbilical ratio is better to predict the adverse perinatal outcome such as fetal distress, small for gestational age babies and neonatal complications like hyperbilirubinemia in cases of IUGR along with the other antenatal surveillance tests.

Funding: No funding sources

Conflict of interest: None declared

Ethical approval: The study was approved by the Institutional Ethics Committee

\section{REFERENCES}

1. Battaglia FC, Lubchenco LO. A practical classification of newborn infants by weight and gestational age. J Pediatr. 1967;71(2):129-33.

2. McIntire DD, Bloom SL, Casey BM, Leveno KJ. Birth weight in relation to morbidity and mortality among newborn infants. $\mathrm{N}$ Eng $\mathrm{J}$ Med. 1999;340(16):1234-8.

3. Fitzgerald DE, Drumm JE. Non-invasive measurement of the human circulation using ultrasound: a new method. BMJ. 1977;2:1450-1.

4. Gramellini D, Folli MC, Raboni S, Vadora E, Merialdi A. Cerebral umbilical Doppler ratio as a predictor of adverse perinatal outcome. Cerebral and umbilical ratio. Obstet Gynecol. 1992;79:416-20.

5. Sharma D, Shastri S, Sharma P. Intrauterine growth restriction: antenatal and postnatal aspects. Clin Med Insights Pediatr. 2016;10:67-83.

6. Arias F. Accuracy of the middle-cerebraltoumbilical-artery resistance index ratio in the prediction of neonatal outcome in patients at high risk for fetal and neonatal complications. Am J Obstet Gynecol. 1994;171:1541-5.

7. Bahado-Singh RO, Kovanci E, Jeffres A, Oz U, Deren O, Copel J, et al. The Doppler cerebroplacental ratio and perinatal outcome in intrauterine growth restriction. Am J Obstet Gynecol. 1999; 180:750-6.

8. Khanduri S, Chhabra S, Yadav S, Sabharwal T, Chaudhary M, Usmani T, et al. Role of color doppler flowmetry in prediction of intrauterine growth retardation in high-risk pregnancy. Cureus. 2017;9(11):e1827.

9. Villar J, Carroli G, Wojdyla D, Abalos E, Giordano $\mathrm{D}$, Ba'aqeel $\mathrm{H}$, et al. Preeclampsia, gestational hypertension and intrauterine growth restriction, related or independent conditions?. Am J Obstet Gynecol. 2006;194(4):921-31.

10. Teixeira MP, Queiroga TP, Mesquita MD. Frequency and risk factors for the birth of small-forgestational-age newborns in a public maternity hospital. Einstein (Sao Paulo). 2016;14(3):317-23.

Cite this article as: Kamalarani AE, Victor SR.

Cerebro-umbilical doppler ratio as a predictor of adverse perinatal outcome. Int J Reprod Contracept Obstet Gynecol 2020;9:710-4. 